\title{
Produção De Cimentos Geopoliméricos Para Mitigação Da Reação Álcali Agregado Em Estruturas De Concreto De Cimento Portland.
}

\author{
M. Valenga ${ }^{1 *}$, R. Przybysz ${ }^{1}$, E. Pereira ${ }^{1,2}$, E. Pereira ${ }^{1,2}$ \\ *Autor de Contacto: matheus.villian.valenga1234@gmail.com \\ ${ }^{1}$ Departamento de Engenharia Civil, Universidade Estadual de Ponta Grossa, Ponta Grossa, Brasil \\ ${ }^{2}$ Programa de Pós-Graduação em Engenharia e Ciência de Materiais, Universidade Estadual de Ponta Grossa, Ponta \\ Grossa, Brasil
}

\section{RESUMO}

O Metacaulim como adição pozolânica pode consumir também álcalis e formar geopolímeros na microestrutura do concreto, sendo que o objetivo deste estudo é utilizá-lo para a mitigação da reação álcali-agregado (RAA) em dois agregados - A (reativo) e B (inócuo). Foram produzidas 3 amostras por ensaio nas porcentagens $0 \%, 5 \%, 10 \%, 15 \%$ e $20 \%$. A metodologia utilizada baseouse em ensaios acelerados em barras de argamassa, compressão axial de corpos de prova e microscopia eletrônica de varredura. A adição mitigou expansões da RAA das amostras, aumentou resistências a compressão para o agregado inócuo e às diminuiu para o agregado reativo. Também se identificou formação de geopolímeros nas microestruturas. O metacaulim mostrou-se um material eficiente para mitigação da RAA e produção de geopolímeros.

Palavras chave: Concreto; Durabilidade; Reação Álcali-Agregado; Mitigação; Geopolímeros.

\section{RESUMEN}


La metacaolina como adición puzolánica también puede consumir álcalis y formar geopolímeros en la microestructura del concreto, el propósito de este estudio es utilizarlo para mitigar la reacción álcali-agregado (RAA) en dos agregados: A (reactivo) y B (inocuo). Se produjeron tres muestras por ensayo en los porcentajes $0 \%, 5 \%, 10 \%, 15 \%$ y 20\%. La metodología utilizada se basó en ensayos acelerados en barras de mortero, compresión axial de cuerpos de prueba y microscopía electronica de barrido. La adición mitigó las expansiones de RAA de las muestras, aumentó la resistencia a la compresión para el agregado inocuo y las disminuyó para el agregado reactivo. También se ha identificado la formación de geopolímeros en las microestructuras. El metacaolín demostró ser un material eficaz para mitigar la RAA y producir geopolímeros.

Palabras llave: Concreto; Durabilidad; Reacción álcali-agregado; Mitigación; Geopolímeros;

\begin{abstract}
Metakaolin as a pozzolanic addition can also consume alkalis and form geopolymers in the concrete microstructure, and the aim of this paper is use it to mitigate the alkali-aggregate reaction (AAR) in two aggregates - A (reactive) and B (innocuous). Three samples were produced per assay at parcentages of $0 \%, 5 \%, 10 \%, 15 \%$ and $20 \%$. The methodology used was based on accelerated tests on mortar bars, axial compression of specimens and scanning electron microscopy. The addition mitigated AAR expansions of the samples, increased compressive strengths for the innocuous aggregate and decreased them for the reactive one. It was also identified the formation of geopolymers in microstructures. Metakaolin proved to be an efficient material for mitigating AAR and producing geopolymers.
\end{abstract}

Key words: Concrete; Durability; Alkali-Aggregate Reaction; Mitigation; Geopolymers; 


\section{INTRODUÇÃO}

A reação álcali-agregado (RAA) é uma das mais conhecidas manifestações patológicas do concreto, que ganhou cada vez mais destaque após sua descoberta no início do século XX por Stanton nos Estados Unidos. Desde então, diversas recomendações surgiram para mitigar os seus efeitos deletérios nas estruturas de concreto de cimento Portland em prol de garantir sua integridade mecânica e durabilidade. As principais precauções a serem tomadas são a não utilização de agregados reativos, utilização de cimento com baixas quantidades de álcalis, uso de aditivos químicos ou a substituição do cimento por materiais cimentícios complementares que não permitam o desenvolvimento da RAA, como cinza volante, sílica ativa, metacaulim, etc. (CarlesGibergues et al., 2008; Chen et al., 1993).

Um dos mecanismos de degradação da RAA se dá pela interação de álcalis $\left(\mathrm{Na}^{+}, \mathrm{K}^{+}\right.$e $\left.\mathrm{Ca}^{+}\right)$e hidroxilas $\left(\mathrm{OH}^{-}\right)$oriundos do processo de hidratação do cimento na solução de poros da estrutura do concreto. Inicia-se com o grupo silanol $(\mathrm{Si}-\mathrm{OH})$ sendo atacado pelas hidroxilas na superfície do agregado liberando água e adquirindo caráter anódico $\left(\mathrm{Si}-\mathrm{O}^{-}\right)$, o qual é balanceado pelos álcalis na solução de poros. A reação continua com o ataque de hidroxilas ao siloxano ( $\mathrm{Si}-\mathrm{O}-\mathrm{Si}$ ) numa camada interior do agregado, sendo necessário adsorção de água e álcalis para atingir estabilidade de cargas além de solubilidade, tendo como produto um gel higroscópico que causa tensões internas devido sua expansão. Em seguida os álcalis $\mathrm{Na}^{+}$e $\mathrm{K}^{+}$dos produtos formados são substituídos por $\mathrm{Ca}^{+}$devido a força de sua ligação ser maior, liberando de forma contínua os cátions monovalentes em solução, tornando o processo da reação renovável até o consumo dos reagentes disponíveis (Broekmans, 2012; Pereira, 2018; Williamson e Juenger, 2016; Zeidan e Said, 2017)

Nesse contexto, as adições têm o papel de impedir o desenvolvimento da reação álcali-agregado utilizando a sílica reativa presente nos agregados para gerar produtos como silicato de cálcio hidratado (CSH) ou estruturas chamadas de geopolímeros (Sakulich et al., 2010). Uma hipótese conhecida é que as adições pozolânicas em geral diminuem a difusão de íons na solução de poros da estrutura além de consumir o hidróxido de cálcio $\left(\mathrm{Ca}(\mathrm{OH})_{2}\right)$ existente mitigando a RAA pela inibição da liberação de $\mathrm{Na}^{+}$e $\mathrm{K}^{+}$, porém a afirmativa deve ser estudada para maior entendimento dos mecanismos das reações e determinação dos produtos formados (Aquino et al., 2001).

O metacaulim é uma adição mineral originada do tratamento térmico de argilas cauliníticas, que devido a desidratação do material cristalino original tem-se como produto aluminossilicatos amorfos de alta pozolanicidade, garantindo alta reatividade com moléculas de Portlandita existente nos poros da matriz cimentícia podendo gerar silicato de cálcio hidratado $(\mathrm{CSH})$, sílico-aluminato de cálcio hidratado $\left(\mathrm{C}_{2} \mathrm{ASH}{ }_{8}\right)$ e aluminato de cálcio hidratado $\left(\mathrm{C}_{3} \mathrm{AH}_{6}\right)($ Do Carmo e Portella, 2008; Gruber et al., 2001). Essas características tornam a adição uma boa opção para a mitigação da reação álcali-agregado, tendo em vista seu potencial reativo com os precursores do gel higroscópico característico da manifestação deletéria na solução de poros da argamassa.

Pouhet e Cyr (2014) em seus estudos constataram que a utilização de metacaulim para argamassas com agregados reativos expostas a solução de hidróxido de sódio mitigou com eficiência as manifestações da reação álcali-agregado. Ramlochan, Thomas e Gruber (2000) declaram que substituições entre $10 \%$ e $15 \%$ de metacaulim em relação ao cimento para confecção de concretos podem controlar totalmente as expansões devido a RAA dependendo da natureza do agregado. Zhou et al. (2015) indicaram que a substituição de até $15 \%$ do cimento por metacaulim em argamassas se mostra consideravelmente mais eficaz que substituições de cinza volante no controle da RAA, reduzindo expansões em mais de 90\% em um período de 3 meses. Os autores expressam que a mitigação da reação álcali-agregado pode estar ligada à redução do $\mathrm{pH}$ nos poros da argamassa e consumo dos álcalis e Portlandita, interrompendo o avanço da reação.

Entretanto, quando da utilização do metacaulim em estruturas de cimento Portland, dependendo das proporções de $\mathrm{Si} / \mathrm{Al}$ da composição química do precursor e álcalis do ativador alcalino 
utilizado, zeólitas são formadas na microestrutura porosa pela cristalização de um gel amorfo em grandes cadeias, originando assim o que é conhecido como concreto geopolimérico (Zhang et al., 2009; Pinto, 2006). A composição e estrutura molecular das zeólitas apresentam variabilidades diversas, porém podem ser representadas pela ligação entre tetraedros de sílica $\left(\mathrm{SiO}_{4}\right)$ e tetraedros de alumínio $\left(\mathrm{AlO}_{4}\right)$ dissolvidos do precursor compartilhando átomos de oxigênio, onde álcalis livres $\left(\mathrm{Na}^{+}, \mathrm{K}^{+}\right.$ou $\left.\mathrm{Ca}^{+2}\right)$ balanceiam ionicamente o alumínio tetravalente, recebendo assim a nomenclatura genérica de (poli)sialato $(\mathrm{Si}-\mathrm{O}-\mathrm{Al}-\mathrm{O})$, (poli)sialato-siloxo $(\mathrm{Si}-\mathrm{O}-\mathrm{Al}-\mathrm{O}-\mathrm{Si}-\mathrm{O})$ ou (poli)sialato-disiloxo ( $\mathrm{Si}-\mathrm{O}-\mathrm{Al}-\mathrm{O}-\mathrm{Si}-\mathrm{O}-\mathrm{Si}-\mathrm{O}$ ), tornando-se tectoaluminossilicatos hidratados (Junior, 2016; Król et a1., 2019; Król e Mozgawa, 2019).

Geopolímeros podem apresentar diversas propriedades e aplicações dependendo das proporções entre seus materiais precursores, como em tijolos, aglomerantes para confecção de concretos, selantes ou adesivos ou materiais resistentes ao fogo (Davidovits, 1991; Junior, 2016). Quando comparado com estruturas de cimento Portland, geopolímeros produzidos nas proporções adequadas e em certas condições de cura, podem apresentar algumas propriedades onde eles se mostram muito competentes, se mostrando superiores nesses aspectos, como resistência química, estabilidade térmica e resistência ao fogo. Outro ponto positivo dos geopolímeros é sua questão ambiental, onde nos processos industriais para a confecção de seus precursores a poluição e liberação de $\mathrm{CO}_{2}$ é quase insignificante perante os procedimentos para fabricação do cimento Portland, que pode chegar até a $10 \%$ das emissões totais de dióxido de carbono mundial, contribuindo aos fatores de preservação do meio ambiente e controle do efeito estufa (Habert et al., 2011; Li et al., 2018).

Desse modo, o objetivo deste trabalho foi analisar a utilização de metacaulim de alta reatividade para a formação de geopolímeros e mitigação de efeitos causados por reações álcali agregado na microestrutura de argamassas de cimento Portland, encontrando a proporção adequada de adição para cada agregado estudado. Além de avaliar as propriedades físico-químicas finais da argamassa após a utilização de metacaulim para a formação de argamassas geopoliméricas.

\section{PROCEDIMIENTO EXPERIMENTAL}

Para o estudo realizado foram utilizados dois agregados diferentes já utilizados anteriormente pelo grupo de pesquisa em materiais de construção civil da Universidade Estadual de Ponta Grossa, nomeados de agregados A (deletério) e B (inócuo). Como aglomerante foi utilizado o cimento Portland CP II F - 32 e a adição pozolânica estudada para produção de concretos geopoliméricos foi um metacaulim de alta reatividade.

A caracterização física dos agregados foi feita seguindo a normativa NBR 7211 (2009) Agregados para concreto - Especificação, sendo os ensaios requisitados a distribuição granulométrica (NBR NM 248: 2003), determinação da massa unitária (NBR 7251: 1982), massa específica real (NBR 9776: 2003), determinação do material pulverulento por lavagem (NBR NM 46: 2003). Além da caracterização física dos agregados, a caracterização química e mineralógica também foi realizada por FRX e DRX.

Primeiramente foi realizado o ensaio acelerado das barras de argamassa conforme a norma ASTM C - 1260/07 para os agregados no traço de 1:2,25:0,47 (cimento:agregado:água) como indicado na normativa, onde a adição de metacaulim foi utilizada como substituição parcial da massa de cimento Portland nas porcentagens de $0 \%, 5 \%, 10 \%, 15 \%$ e $20 \%$ com 3 barras por porcentagem, totalizando 15 barras por agregado. Ainda no estado fresco foi realizado o ensaio para determinação do índice de consistência médio com o intuito de analisar o estado reológico do material a fim de identificar os efeitos da adição na consistência da mistura. Na Figura 1 algumas das barras que foram moldadas no trabalho e o equipamento utilizado para determinação das expansões lineares. 


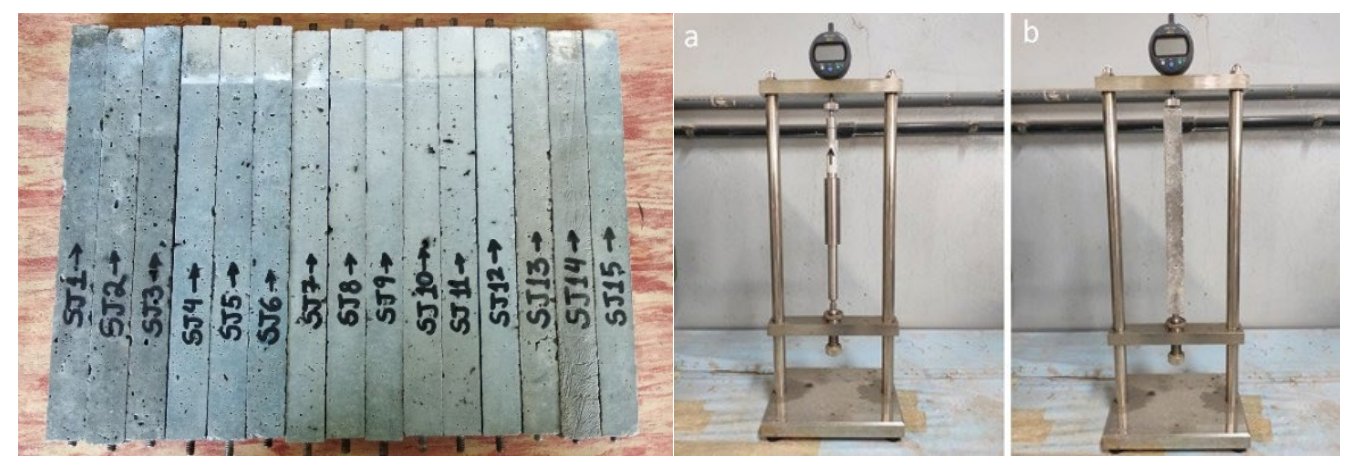

Figura 1 - Amostras referentes ao ensaio acelerado das barras de argamassa e o equipamento com relógio micrométrico utilizado durante o trabalho.

Com a moldagem das barras, foi executado o monitoramento das expansões lineares das amostras imersas por 60 dias em uma solução de hidróxido de sódio $(\mathrm{NaOH})$ em proporção de $1 \mathrm{~mol} / 1$, a uma temperatura de $80^{\circ} \mathrm{C}$. Deve-se ressaltar que este período adotado para o monitoramento das barras é superior ao estipulado por norma (16 dias apenas) para a simulação de um ambiente mais agressivo de cura, potencializando assim o desenvolvimento da reação álcali-agregado. Também foram moldados 6 corpos de prova de argamassa cilíndricos de $10 \mathrm{~cm}$ de altura e $5 \mathrm{~cm}$ de diâmetro em cada porcentagem, sendo um total de 30 por agregado, para avaliação de sua resistência à compressão axial e teores de absorção de água por imersão (NBR 9778: 1987). Os corpos de prova ficaram em imersão na mesma solução que as argamassas para simular os mesmos efeitos nas diferentes amostras, e foram realizados rompimentos aos 28 e 60 dias de idade para análise mais criteriosa dos ganhos de resistência nas argamassas.

Após esses ensaios, amostras menores foram feitas a partir das barras e corpos de prova para ensaios de microscopia eletrônica de varredura, tendo em vista que a presença de metacaulim na mistura pode alterar quimicamente os materiais encontrados nos poros da argamassa. Dependendo dos produtos formados na microestrutura, em conjunto com os demais resultados, pôde-se classificar de maneira mais assertiva se o uso da adição para a formação de cimentos geopoliméricos nas proporções estudadas é devidamente eficaz.

\section{RESULTADOS E DISCUSSÕES}

Os agregados apresentam semelhanças quanto algumas propriedades físicas, como massa específica real e unitária, além de grandes percentuais de material pulverulento (parcela de material passante na peneira de abertura de 200 micrômetros) fato este que está ligado aos agregados serem obtidos por britagem de rocha sã. Quanto a suas composições químicas, ambos são constituídos predominantemente por sílica $\left(\mathrm{SiO}_{2}\right)$ com quantidades consideráveis de óxido de alumínio $\left(\mathrm{Al}_{2} \mathrm{O}_{3}\right)$ e demais compostos de sódio, potássio, cálcio e outros elementos, o que condiz com sua composição mineralógica baseada em quartzo, plagioclásios e filossilicatos. Os dados das caracterizações dos agregados estão organizados nas tabelas 1 e 2 a seguir:

Tabela 1 - Propriedades físicas dos agregados A e B.

\begin{tabular}{|c|c|c|c|c|c|c|}
\hline \multirow[t]{2}{*}{ Areia } & \multirow[t]{2}{*}{ DMC } & \multirow[t]{2}{*}{ MF } & $\begin{array}{l}\text { Massa } \\
\text { Específica Real }\end{array}$ & $\begin{array}{l}\text { Massa } \\
\text { Unitária }\end{array}$ & Pulverulento & Absorção \\
\hline & & & \multicolumn{2}{|l|}{$\left(\mathrm{g} / \mathrm{cm}^{3}\right)$} & \multicolumn{2}{|l|}{$(\%)$} \\
\hline A & 2,4 & 2,2 & 2,778 & 1,48 & 21,08 & 1,39 \\
\hline B & 4,8 & 2,55 & 2,597 & 1,43 & 15,08 & 2,27 \\
\hline
\end{tabular}


Tabela 2 - Composição química e mineralógica dos agregados A e B.

\begin{tabular}{|l|l|l|l|l|l|l|l|l|l|l|}
\hline \multirow{3}{*}{ Agregado } & \multicolumn{4}{|l|}{ Óxidos (\%) } \\
\cline { 2 - 11 } & $\mathbf{C O}_{2}$ & $\mathbf{N a}_{2} \mathbf{O}$ & $\mathbf{A l}_{2} \mathbf{O}_{3}$ & $\mathbf{S i O}_{2}$ & $\mathbf{K}_{2} \mathbf{O}$ & $\mathbf{C a O}$ & $\mathbf{F e}_{2} \mathbf{O}_{3}$ & Plag. & Quartzo & Filos. \\
\hline $\mathrm{A}$ & 4,87 & 2,99 & 15,00 & 55,90 & 4,14 & 4,32 & 7,64 & x & x & x \\
\hline $\mathrm{B}$ & 5,52 & 5,40 & 14,30 & 66,00 & 4,58 & 1,26 & 2,51 & x & x & - \\
\hline
\end{tabular}

Como já mencionado, após a mistura das argamassas e antes das moldagens, foi realizado o ensaio para determinação do índice de consistência médio na mesa de adensamento. O procedimento foi realizado para todas as misturas e notou-se que à medida que as quantidades de adição aumentavam, a argamassa se tornava menos fluida e esse padrão foi observado tanto para $o$ agregado A quanto para o agregado B. Como o metacaulim se trata de um material de elevada finura, suas partículas tendem a adsorver parte da água de amassamento, e como a adição ainda é mais leve que o cimento, esse efeito é potencializado pela maior quantidade de partículas necessárias para a substituição em massa do aglomerante. Desse modo, é recomendável que quando da utilização de metacaulim para substituição de cimento em argamassas, e que esta ocorra em porcentagens elevadas, também seja considerada a adoção de aditivos plastificantes para correção da consistência da mistura para a devida utilização. Os dados obtidos pelo ensaio podem ser vistos na Figura 2:

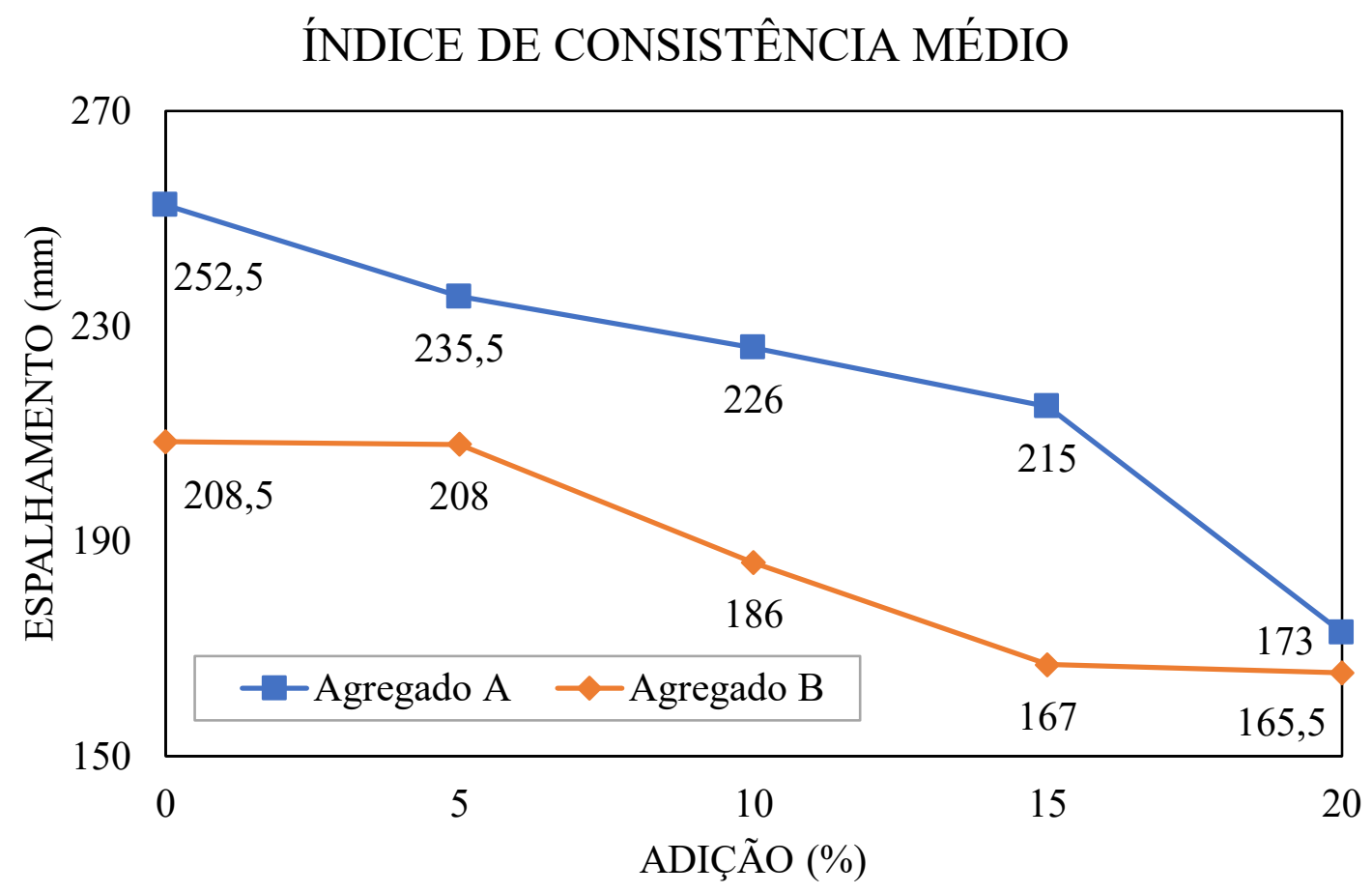

Figura 2 - Relação entre o aumento da quantidade de metacaulim e a consistência das argamassas dos agregados reativo (A) e inerte (B).

Quanto ao ensaio acelerado das barras de argamassa, para o agregado A, a substituição de metacaulim em relação ao cimento resultou na mitigação das expansões devido a reação álcali- 
agregado. É possível verificar pelo gráfico da Figura 3 que nas barras com $0 \%$ de adição suas expansões atingiram valores acima de $0,2 \%$, que pela ASTM C - 1260/07 o agregado é considerado deletério, apresentando as maiores expansões entre as demais amostras (acima de 0,3\% aos 60 dias). Com o aumento das porcentagens de metacaulim, foi identificado uma redução gradual das expansões lineares, chegando a um valor mínimo muito próximo a $0,1 \%$, sendo considerado potencialmente deletério, referente ao traço com $20 \%$ de metacaulim na mistura. É também visível pelo gráfico da Figura 3 que as porcentagens de metacaulim mais eficientes para a mitigação da RAA foram as de $15 \%$ e $20 \%$, pois apresentaram as maiores taxas de variação nas expansões das barras ao longo dos 60 dias de monitoramento. Os resultados do ensaio acelerado referente ao agregado A estão apresentados na Figura 3.

Para as barras referentes ao agregado B também foi observado um padrão de redução nas expansões lineares com o uso do metacaulim, entretanto a taxa de variação foi menor quando compara às barras do agregado A. Pelo fato do agregado em questão não ser reativo suas expansões lineares sem a adição pozolânica, ou até para até $5 \%$ de metacaulim, não são muito superiores a $0,1 \%$ do seu comprimento aos 60 dias, já não tendo potencial reativo de acordo com a ASTM C - 1260/07, sendo classificado como potencialmente deletério com essas porcentagens de metacaulim. Somente a partir de $10 \%$ de substituição de cimento pela adição foi observado uma maior diminuição nas expansões das amostras, chegando a um valor máximo de $0,05 \%$ aos 60 dias de idade para a substituição de $20 \%$ de metacaulim, o que indicaria um agregado completamente inócuo pelos limites de expansão da normativa. As expansões das barras do agregado B estão apresentadas na Figura 4:

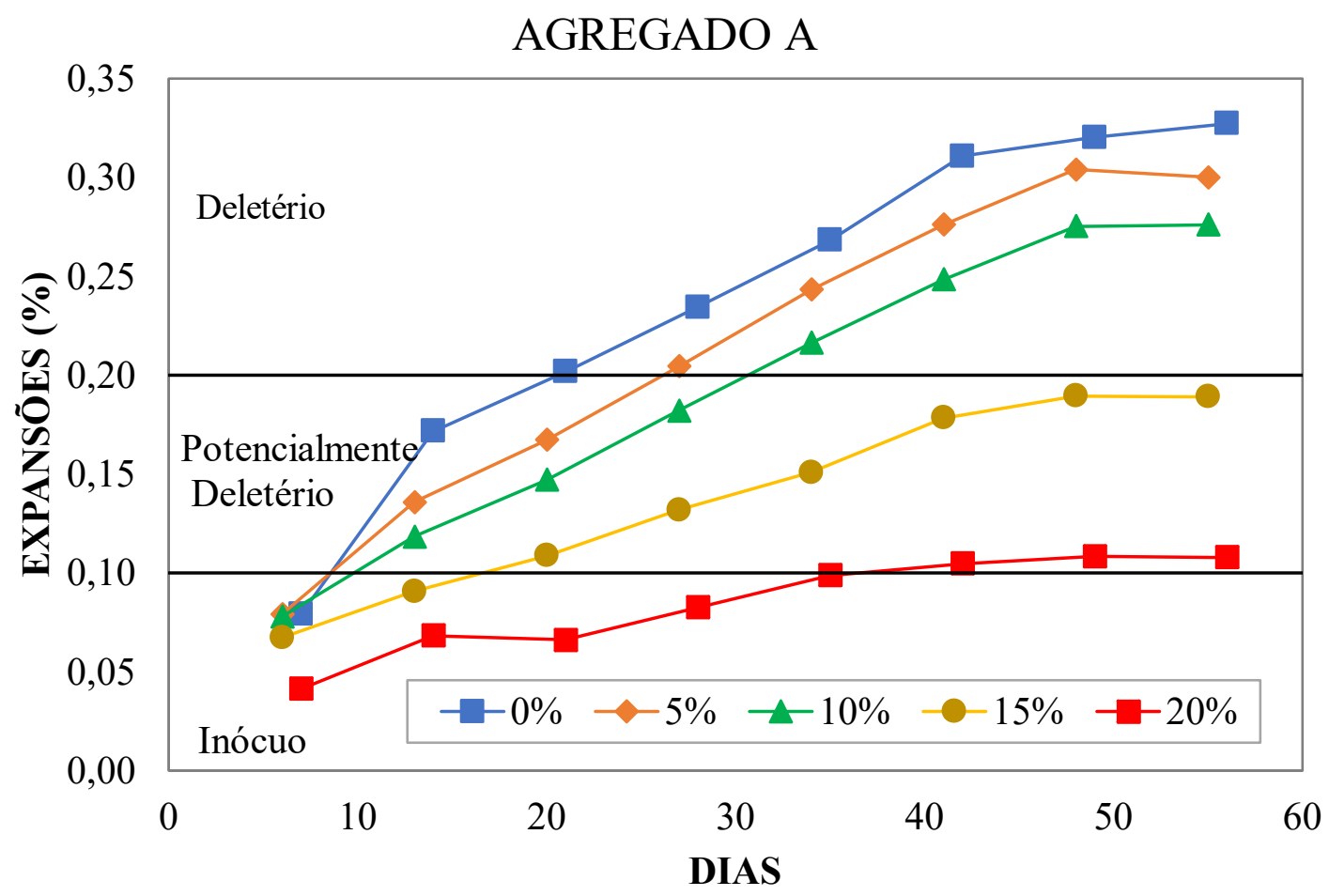

Figura 3 - Expansão linear das barras de argamassa do agregado A com substituições de metacaulim ao longo de 60 dias. 


\section{AGREGADO B}

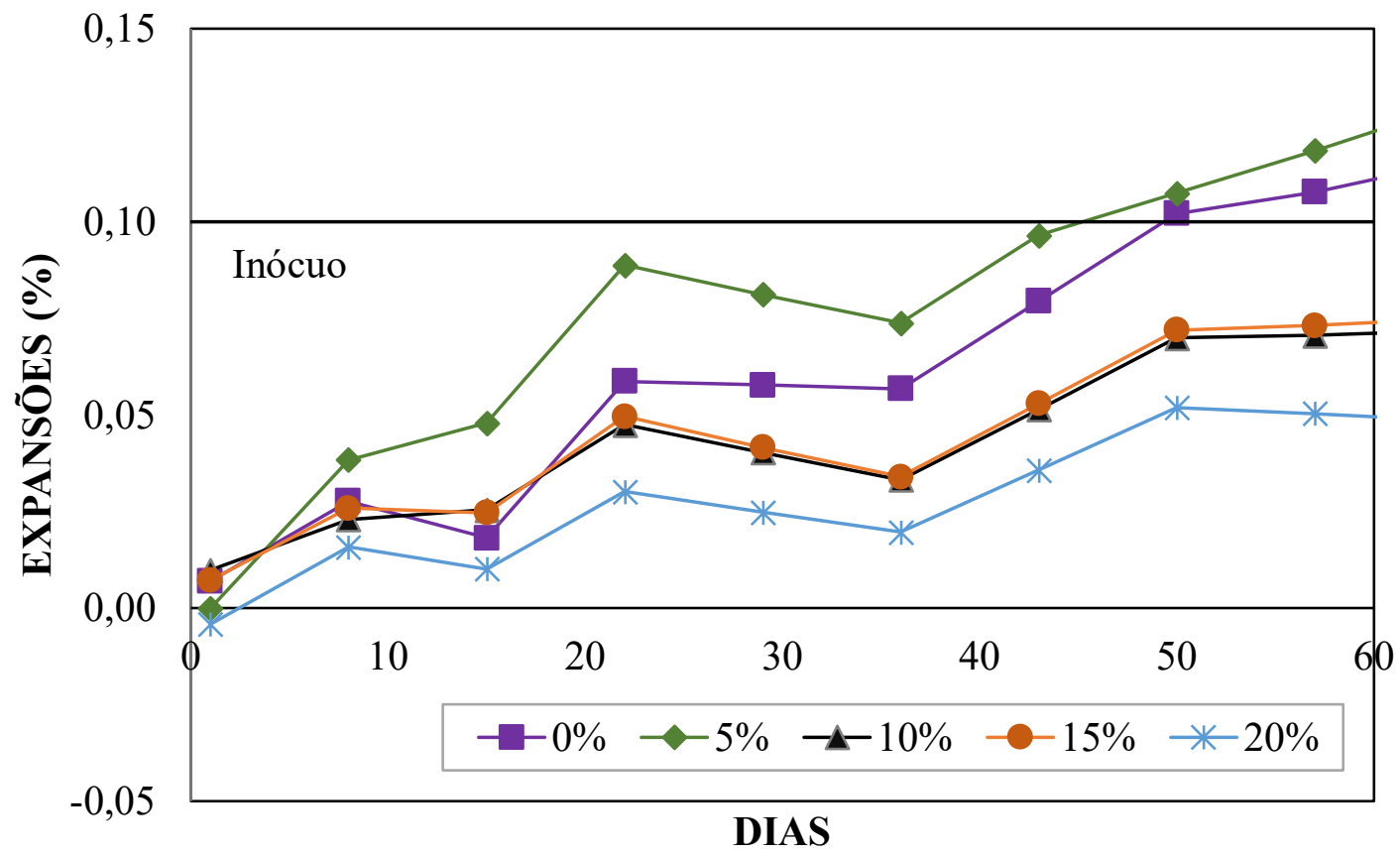

Figura 4 - Expansão linear das barras de argamassa do agregado B com substituições de metacaulim ao longo de 60 dias.

O comportamento observado nas barras de argamassa, tanto em maior quanto em menor escala, está ligado a ação do metacaulim na microestrutura porosa delas, porém este fenômeno pode estar ligado tanto ao consumo de Portlandita, produto da hidratação do cimento residente dos poros da microestrutura, para a formação de silicato de cálcio hidratado $(\mathrm{CSH})$, quanto ao consumo de álcalis livres como $\mathrm{Na}^{+}$ou $\mathrm{K}^{+}$para que com o ativador alcalino do ambiente ocorra a policondensação dos materiais em geopolímeros, pois sem analisar a microestrutura das amostras é impossível indicar com assertividade qual dos mecanismos de mitigação da patologia proporcionou esse comportamento às argamassas.

Para o ensaio de compressão axial dos corpos de prova cilíndricos, aos 28 dias com o aumento da adição nas argamassas referentes ao agregado A foi observado uma gradual diminuição das tensões de ruptura, ao passo que no agregado B não foi identificada grandes variações nas resistências obtidas devido a adição. Já aos 60 dias de idade os padrões observados foram basicamente os mesmos: diminuição gradual da resistência a compressão para o agregado A com o aumento de metacaulim na mistura e para o agregado B variações mais acentuadas, mas ainda não expressivas nas resistências a compressão.

Ressalta-se que a diminuição nas resistências dos corpos de prova referentes ao agregado A foram mais severas aos 60 dias do que na idade de 28 dias mesmo considerando a maior inconsistência dos dados obtidos, chegando a apresentar valores mais de 50\% abaixo que o traço sem adições. Esse comportamento pode indicar que para o agregado B houve formação de CSH na microestrutura devido ao efeito pozolânico da adição, e para o agregado A formação de geopolímeros pela interação entre fases reativas e o metacaulim, mas com resistências a compressão não satisfatórias. Os resultados foram obtidos pelas rupturas de 3 corpos de prova de cada porcentagem dos 2 agregados e os respectivos valores médios podem ser observados na Figura 5 e Figura 6: 


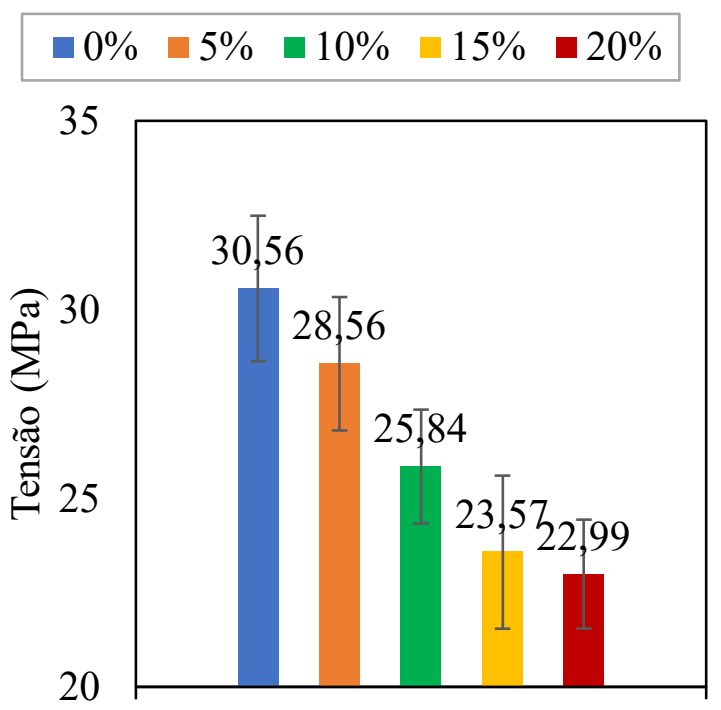

A

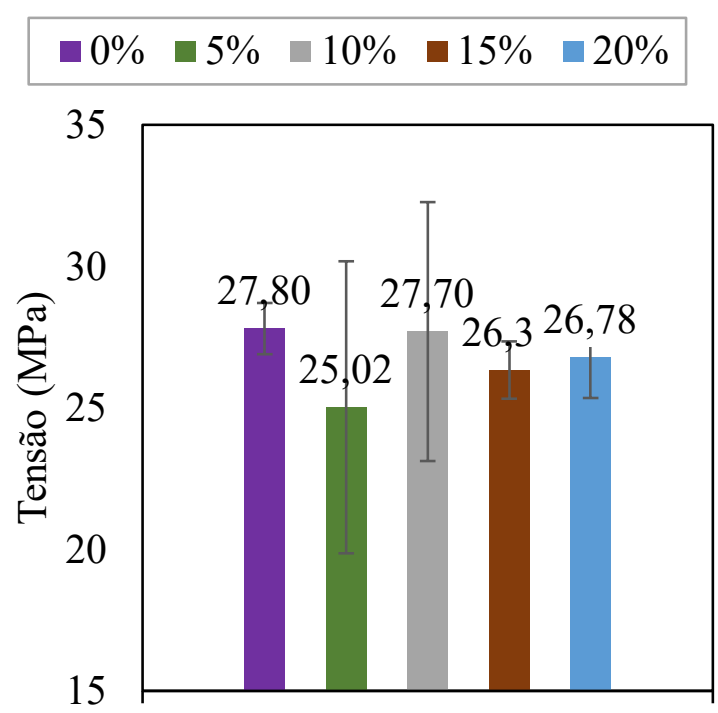

$\mathrm{B}$

Figura 5 - Resistência a compressão axial dos agregados A e B aos 28 dias.

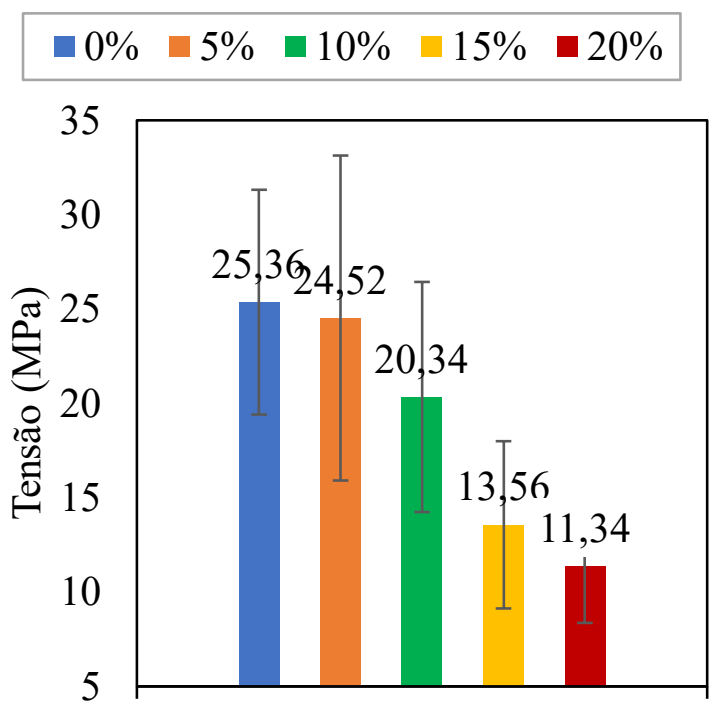

A

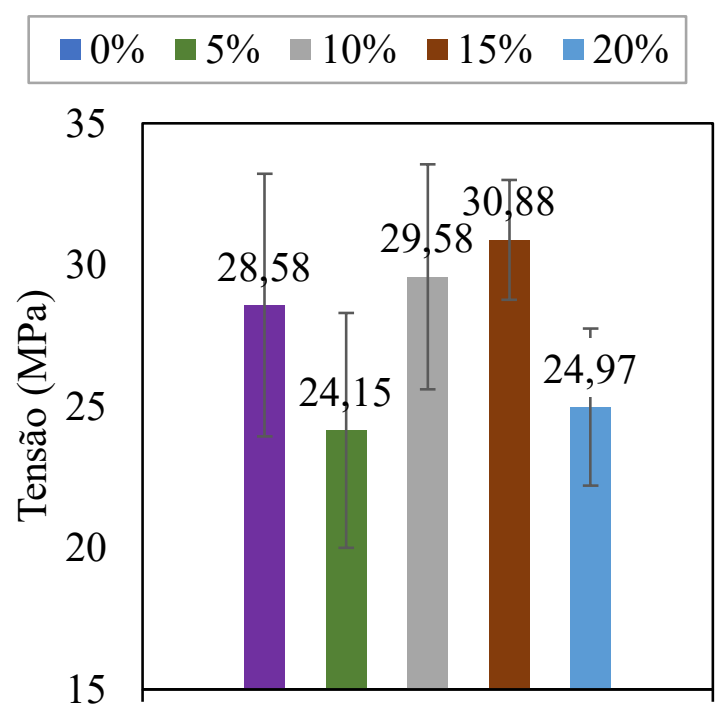

B

Figura 6 - Resistência a compressão axial dos agregados A e B aos 60 dias.

O ensaio de absorção por imersão foi realizado com as demais amostras em paralelo a ruptura dos corpos de prova cilíndricos. Para o agregado A tanto aos 28 quanto aos 60 dias não foi possível identificar um padrão específico nas variações dessa propriedade nos corpos de prova do ensaio, não apresentando variações expressivas em torno de 7,5\% aos 28 dias e 8,5\% aos 60 dias. Nos corpos de prova do agregado B, no entanto, foi observado um aumento das absorções com maiores porcentagens de metacaulim, sendo identificado padrão associado à quantidade de adição na mistura das argamassas, onde este comportamento foi identificado para as amostras com 28 e 60 dias. Porém, observando estas variações, foi identificado um pequeno aumento nos valores de absorção para as idades mais avançadas, fato similar ao ocorrido com as amostras do agregado A. Esse comportamento provavelmente está ligado ao desenvolvimento da RAA, pelo processo de expansão e consequente fissuração, ocasionada das tensões internas promovidas pelo gel higroscópico característico da manifestação patológica, mas como as variações obtidas são de 
pequena escala, presume-se que o metacaulim está reagindo e diminuindo os efeitos deletérios pela formação de compostos geopoliméricos ou CSH na argamassa. Os resultados obtidos no ensaio de absorção por imersão dos corpos de prova aos 28 e 60 dias podem ser vistos nas figuras 7 e 8 :

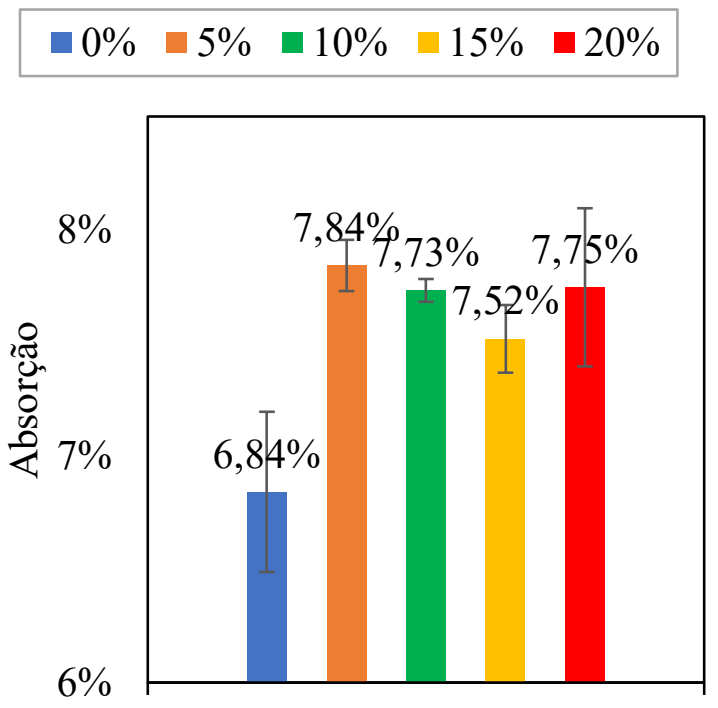

A

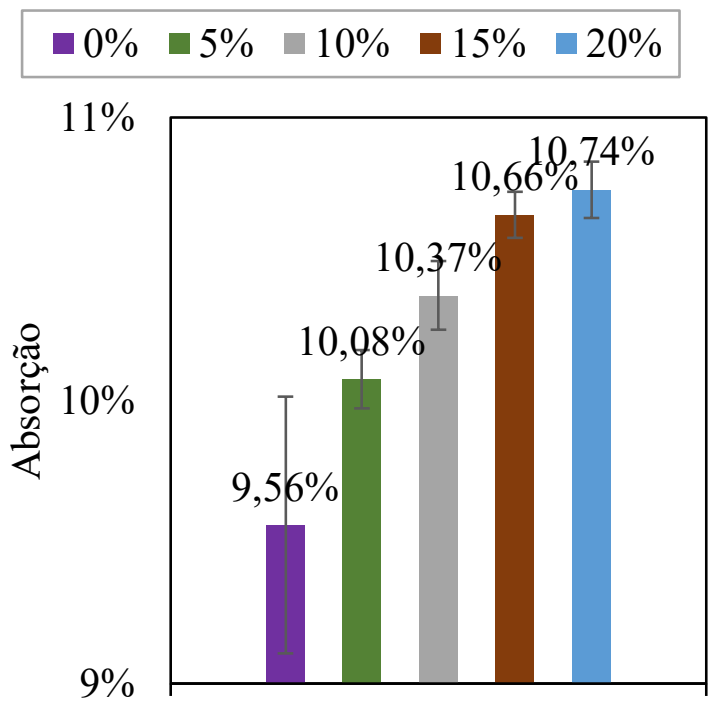

B

Figura 7 - Teores de absorção de água por imersão dos corpos de prova dos agregados A e B aos 28 dias.
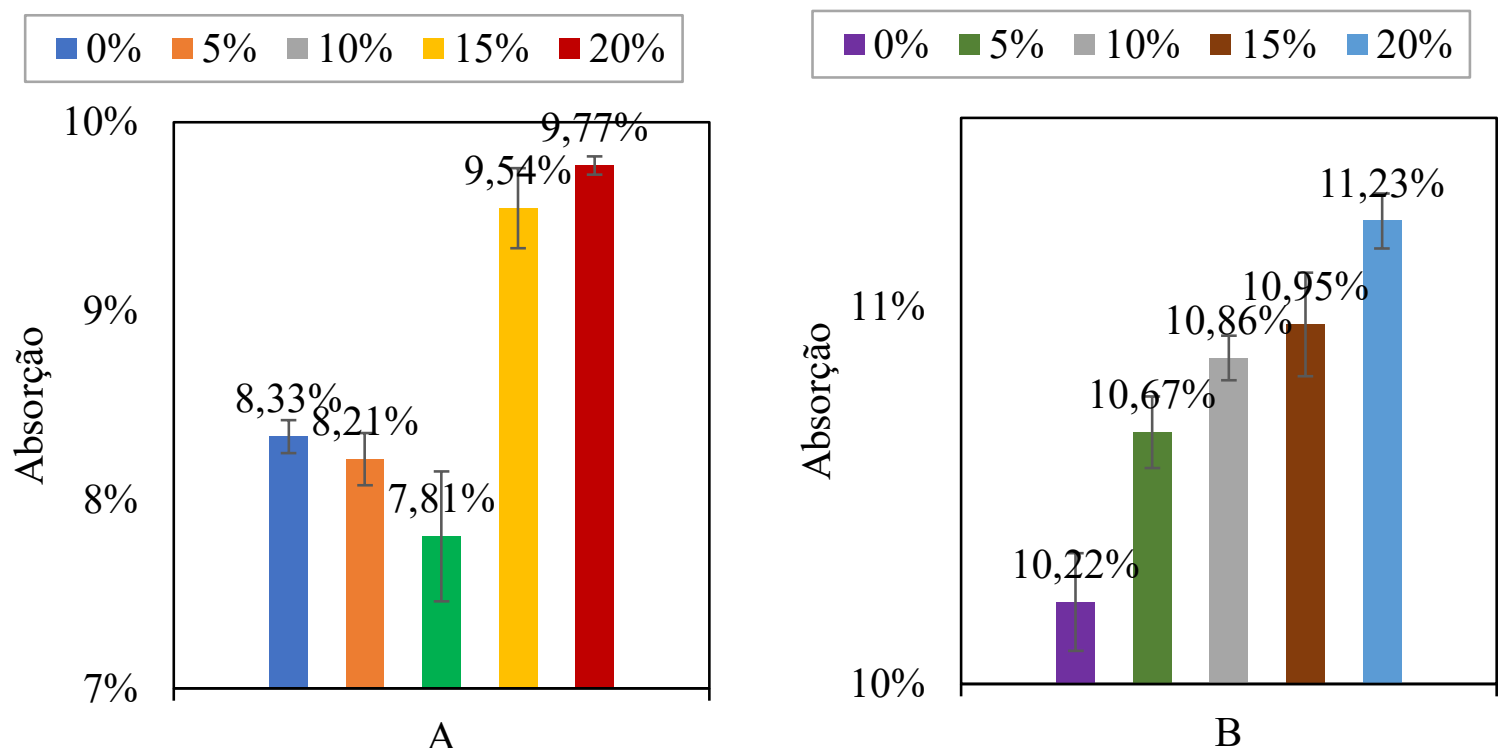

Figura 8 - Teores de absorção de água por imersão dos corpos de prova dos agregados A e B aos 60 dias.

O fato de a adição não apresentar um padrão bem definido para as amostras do agregado deletério A pode estar ligado às propriedades da adição pozolânica, que em diferentes proporções com os materiais precursores e ativador alcalino, reagem em produtos com propriedades específicas. Como o agregado é deletério ele apresenta em sua composição fases reativas que reagem com o metacaulim para a policondensação, e como há a variação das porcentagens de metacaulim na mistura da argamassa, a proporção $\mathrm{Si} / \mathrm{Al}$ também é alterada, podendo gerar geopolímeros com 
arranjos moleculares diferentes. Na hipótese da formação de produtos da policondensação com propriedades distintas para cada porcentagem de adição, o preenchimento dos poros da microestrutura por geopolímeros seria afetado, o que alteraria diretamente a taxa de absorção da argamassa, bem como as resistências mecânicas.

Nos corpos de prova do agregado B, o comportamento que foi observado pode estar ligado ao aumento da porosidade na argamassa, que ocorre com o aumento do fator água/cimento proporcionado pelas maiores porcentagens de adição. À medida que a substituição de cimento por metacaulim aumenta sem alterar as quantidades de água, a relação entre água e aglomerante não se mantem constante na mistura, proporcionando menores resistências às argamassas com quantidades elevadas de adição, evento este que tem relação direta na absorção de água das amostras. Contudo o aumento da absorção apresenta pouca variação, o que pode indicar que houve o tamponamento dos poros por produtos da geopolimerização ou por silicato de cálcio hidratado devido a ação da adição.

Deu-se continuidade para as microscopias de amostras preparadas a partir das barras de argamassa do ensaio acelerado e quanto as argamassas feitas com o agregado A, por ser um material reativo, na microestrutura das amostras com $0 \%$ de adição, foi possível observar a formação do gel característico da reação álcali-agregado gretado nos poros da matriz cimentícia, além de outros produtos como cristais de etringita que podem ser observados na Figura 10. Enquanto que nos poros da argamassa com $20 \%$ de metacaulim, não é possível identificar as manifestações da RAA, o que pode indicar o consumo dos álcalis para a formação de geopolímeros ou consumo de Portlandita para produção de CSH.

Entretanto, ao considerar os resultados anteriores, onde o metacaulim se mostrou eficiente para a mitigação das expansões devido a reação álcali-agregado, como demonstrado na Figura 3, porém reduziu as resistências a compressão axial em relação ao traço inicial com o aumento do percentual da adição, mostra que sua utilização não foi plenamente benéfica para as amostras do agregado reativo. Este comportamento pode estar ligado aos resultados apresentados por Mahanama et al. em 2019, onde os autores indicam que argamassas geopoliméricas com elevados teores de cálcio podem não ser adequadas para a mitigação da reação álcali-agregado, e como o tipo de cimento utilizado durante o trabalho pode conter até $10 \%$ de filer calcário, a proporção deste material com a adição pozolânica estaria aproximadamente dentro dos teores não indicados de quantidade de cálcio para que os geopolímeros assegurassem a integridade das argamassas perante a RAA.
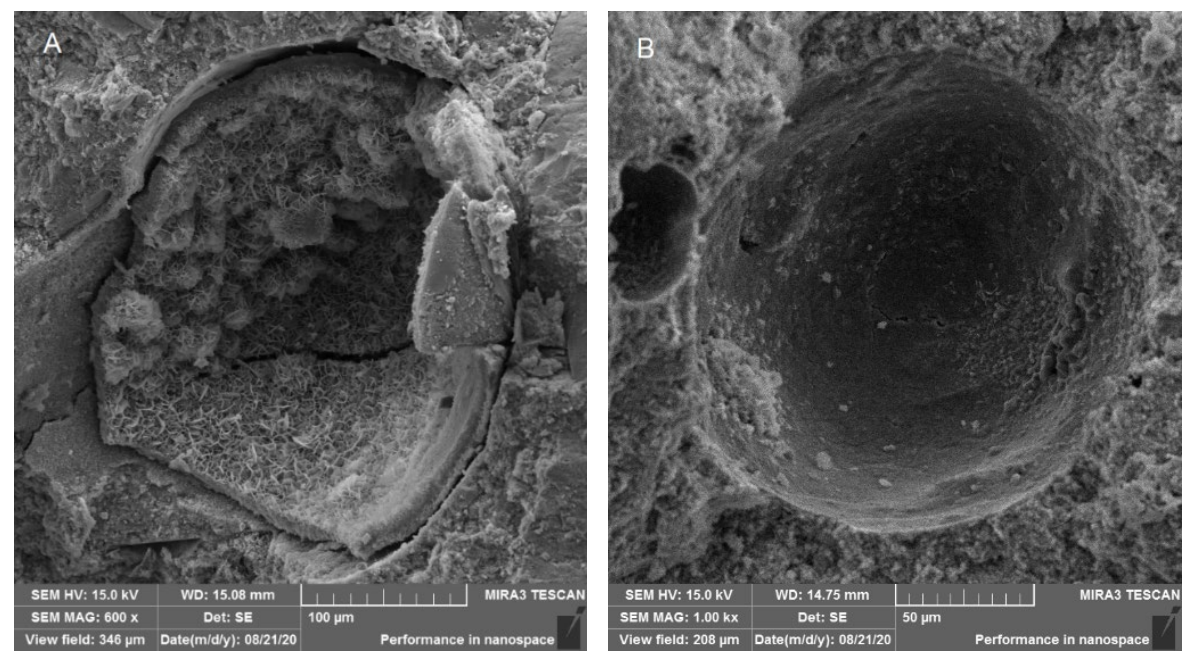

Figura 9 - a) Poro da argamassa A sem metacaulim; b) Poro da argamassa A com $20 \%$ de metacaulim. 
As microscopias referentes ao agregado B mostraram produtos condizentes com os demais resultados do trabalho. Para o traço com $0 \%$ de metacaulim, na microestrutura não foi observado em quantidades elevadas dos produtos da RAA, certamente ligado a baixa reatividade do agregado. Com maiores quantidades de metacaulim, alguns sinais de geopolímeros foram detectados nas imagens retiradas, onde que para a porcentagem de $20 \%$ produtos com aspectos muito semelhantes aos encontrados por Sanchindapong et al. (2020) em seu trabalho com cinza volante em cimentos álcali ativados foram identificados, onde é visível uma estrutura de cristais interligados semelhante a uma esponja.

Ao conciliar esses dados com o fato das expansões lineares devido RAA diminuírem, mesmo este sendo um agregado inócuo, e o incremento das resistências nos corpos de prova cilíndricos para 28 e 60 dias, é fortalecida a hipótese de que houve a formação de geopolímeros na microestrutura da argamassa do agregado B. Abaixo estão as imagens dos poros da argamassa em questão:
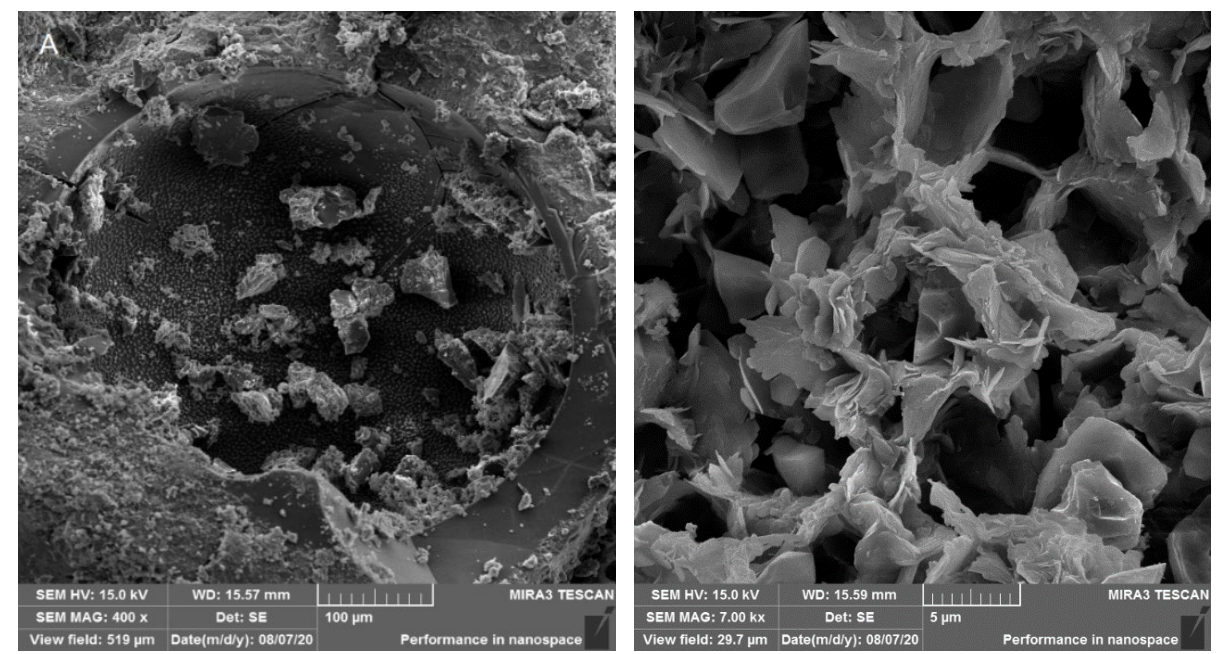

Figura 10 - a) Poro da argamassa B sem metacaulim; b) Estruturas identificadas na matriz cimentícia da argamassa com $20 \%$ de metacaulim.

\section{CONCLUSÕES}

O uso de metacaulim para formação de geopolímeros e mitigação da reação álcali-agregado para o agregado inócuo " $\mathrm{B}$ " se mostrou eficiente para as substituições entre $15 \%$ e $20 \%$, pelo fato que além da redução das expansões lineares de suas barras prismáticas de argamassa com o uso da adição, não foram observados reduções de suas resistências nos corpos de prova cilíndricos e houve formação de geopolímeros, mesmo que em pequena escala na sua microestrutura porosa.

Enquanto que para o agregado reativo "A", em nenhuma das porcentagens estudadas a adição não se mostrou tão eficiente, tendo em vista que a adição somente reduziu as expansões devido a RAA no ensaio acelerado, não sendo possível identificar com eficiência produtos da geopolimerização em seus poros e ainda reduzindo a resistência mecânica da argamassa gradativamente, sendo não recomendada a utilização da adição sem adequar as proporções corretamente entre o precursor, o ativador alcalino e os compostos potencialmente reativos existentes no agregado, para assim garantir melhores condições para as reações ocorrerem de forma adequada, garantindo assim a formação de cimentos geopoliméricos de alta qualidade. 


\section{AGRADECIMENTOS}

À Universidade Estadual de Ponta Grossa, especialmente ao complexo de laboratórios multiusuários CLABMU pela infraestrutura. A empresa Metacaulim do Brasil pela doação do material utilizado durante o trabalho. E ao Conselho Nacional de Desenvolvimento Científico e Tecnológico $(\mathrm{CNPq})$ pelo convênio da bolsa de estudos.

\section{REFERÊNCIAS}

ASTM International. (2007). ASTM C - 289/07: Standard Test Method for Potential Alkali-Silica Reactivity of Aggregates (Chemical Method). http://www.astm.org/cgi-bin/resolver.cgi?C289

. (2007). ASTM C - 1260/07: Standard Test Method for Potential Alkali Reactivity of $\overline{\text { Aggregates (Mortar-Bar Method). http://www.astm.org/cgi-bin/resolver.cgi?C1260 }}$

Associação Brasileira De Normas Técnicas. (2009). NBR 7211 Agregado para concretoEspecificação. Rio de Janeiro.

de Janeiro.

. (1982). NBR 7251 Agregado em estado solto - Determinação da massa unitária. Rio

. (2003). NBR 9776 Agregados - Determinação da massa especifica de agregados miúdos por meio do frasco Chapman. Rio de Janeiro.

de Janeiro.

. (2003). NBR NM 248 Agregados - Determinação da composição granulométrica. Rio

. (2001). NBR NM 30 Agregado miúdo - Determinação da absorção de água. Rio de Janeiro.

. (2003). NBR NM 46 Agregados - Determinação do material fino que passa através da peneira 75 micrômetros, por lavagem. Rio de Janeiro.

. (1987). NBR 9778 Argamassa e concreto endurecidos - Determinação da absorção de água por imersão - Índice de vazios e massa específica. Rio de Janeiro.

Aquino, W.; Lange, D. A. e Olek, J. The influence of metakaolin and silica fume on the chemistry of alkali-silica reaction products. Cement and Concrete Composites, v. 23, n. 6, p. 485-493, dez. 2001. DOI: 10.1016/S0958-9465(00)00096-2. .

Broekmans, M. A. T. M. Deleterious reactions of aggregate with alkalis in concrete. Reviews in Mineralogy and Geochemistry. [S.1: s.n.]. , 2012

Carles-Gibergues, A. et al. A simple way to mitigate alkali-silica reaction. Materials and Structures/Materiaux et Constructions, v. 41, n. 1, p. 73-83, jan. 2008. DOI: 10.1617/s11527-0069220-у. .

Chen, H.; Soles, J. A. e Malhotra, V. M. Investigations of supplementary cementing materials for reducing alkali-aggregate reactions. Cement and Concrete Composites, v. 15, n. 1-2, p. 75-84, 
1993. DOI: 10.1016/0958-9465(93)90039-c. .

Davidovits, J. Geopolymers - Inorganic polymeric new materials. Journal of Thermal Analysis, v. 37, n. 8, p. 1633-1656, ago. 1991. DOI: 10.1007/BF01912193. Disponível em: http://link.springer.com/10.1007/BF01912193. Acesso em: 28 jan. 2020.

Do Carmo, J. B.M. e Portella, K. F. Estudo comparativo do desempenho mecânico da sílica ativa e do metacaulim como adições químicas minerais em estruturas de concreto. Ceramica, v. 54, n. 331, p. 309-318, 2008. DOI: 10.1590/s0366-69132008000300007. .

Gruber, K. A. et al. Increasing concrete durability with high-reactivity metakaolin. Cement and Concrete Composites, v. 23, n. 6, p. 479-484, dez. 2001. DOI: 10.1016/S0958-9465(00)00097-4.

Habert, G.; D'Espinose De Lacaillerie, J. B. e Roussel, N. An environmental evaluation of geopolymer based concrete production: Reviewing current research trends. Journal of Cleaner Production, v. 19, n. 11, p. 1229-1238, jul. 2011. DOI: 10.1016/j.jclepro.2011.03.012. Disponível em: https://linkinghub.elsevier.com/retrieve/pii/S0959652611000886. Acesso em: 28 jan. 2020.

Junior, L. C. M. L. O Uso Do Vidro Reciclado Como Precursor De Sistemas Cimentantes Geopoliméricos. 2016. 116 f. Dissertação de Mestrado. Universidade Estadual de Ponta Grossa, 2016.

Król, M. et al. ATR/FT-IR studies of zeolite formation during alkali-activation of metakaolin. Solid State Sciences, v. 94, p. 114-119, 1 ago. 2019. DOI: 10.1016/j.solidstatesciences.2019.06.004. .

Król, M. e Mozgawa, W. Zeolite layer on metakaolin-based support. Microporous and Mesoporous Materials, v. 282, p. 109-113, 1 jul. 2019. DOI: 10.1016/j.micromeso.2019.03.028. .

Li, N. et al. Some Progresses in the Challenges for Geopolymer. 431., 2018, Anais [...] [S.1: s.n.], 2018. DOI: 10.1088/1757-899X/431/2/022003.

Mahanama, D. et al. Evaluating Effect of GGBFS in Alkali-Silica Reaction in Geopolymer Mortar with Accelerated Mortar Bar Test. Journal of Materials in Civil Engineering, v. 31, n. 8, p. 1-11, 2019. DOI: 10.1061/(ASCE)MT.1943-5533.0002804. .

Pererira, E. Efeito Da Reação Álcali-Agregado (Raa) Associada Ao Ataque Interno Por Sulfato (Isa) Na Absorção E Porosidade De Compósito De Matriz Cimentícia. 2018. 207 f. Dissertação de Mestrado. Universidade Estadual de Ponta Grossa, 2018. DOI: 10.1017/CBO9781107415324.004.

Pouhet, R. e Cyr, M. Alkali-silica reaction in metakaolin-based geopolymer mortar. Materials and Structures/Materiaux et Constructions, v. 48, n. 3, p. 571-583, 2014. DOI: 10.1617/s11527-0140445-x. .

Ramlochan, T.; Thomas, M. e Gruber, K. A. Effect of metakaolin on alkali-silica reaction in concrete. Cement and Concrete Research, v. 30, n. 3, p. 339-344, 2000. DOI: 10.1016/S00088846(99)00261-6. .

Sakulich, A. R. et al. Influence of Si: Al ratio on the microstructural and mechanical properties of a fine-limestone aggregate alkali-activated slag concrete. Materials and Structures/Materiaux et 
Constructions, v. 43, n. 7, p. 1025-1035, ago. 2010. DOI: 10.1617/s11527-009-9563-2. . 